\title{
The Impact of Housing Market Segmentation between Tourists and Residents on the Hedonic Price for Landscape Quality
}

\author{
Nils Soguel ${ }^{a}$, Marc-Jean Martin $^{\mathrm{b}}$ and Alexandre Tangerini ${ }^{\mathrm{a}}$
}

JEL-Classification: D49, Q26, Q51

Keywords: Hedonic prices method, Market segmentation, Landscape quality, Landscape value, MACBETH

\section{Introduction}

Market segmentation has long been a controversial empirical issue in the use of the hedonic price method. It happens when a given market, such as housing, is organised into a series of submarkets each of them showing a unique functional relationship between prices and (property) attributes. If segmentation does exist, estimating a single hedonic price function for the whole market provides faulty estimates of the implicit prices. A bias in implicit prices is especially problematical when the hedonic price technique utilises the considered market to estimate economic values for environmental services, like landscape. The very idea of the method is to overtake the problem of the absence of clearly defined markets for environmental resources and to observe some surrogate market instead. The most common markets used as surrogates are those for property or labour. Therefore any bias in implicit price for an environmental amenity is all the more damaging as few alternative techniques may exist.

Segmentation does not render the hedonic pricing technique invalid. Rather it makes its use more difficult, as separate functions must be computed for each

a Institut de hautes études en administration publique-IDHEAP/Swiss Graduate School of Public Administration, University of Lausanne, Switzerland.

b Service cantonal de recherche et d'information statistiques-SCRIS/ Statistical Office of the Canton of Vaud.

Corresponding author: nsoguel@idheap.unil.ch. The research benefited from the support of the Swiss National Research Foundation allocated as part of the National Research Program 48 "Landscapes and habitats of the Alps". Helpful comments by Anil Markandya, Tim Taylor and the editors of this special issue are gratefully acknowledged. 
segment. This requires an appropriate basis for segmentation to be identified. As for housing markets, segmentation is often described on the basis of spatial effects or neighbourhood boundaries. The data set is then stratified according to income, accessibility to employment, or household social status.

Segmentation may also come as a result of significant differences in the demand or in the supply structure. The rental housing market in tourist destinations is an obvious example. One can expect the structure of demand to vary between tourists and residents, just as one can expect the structure of supply to differ between apartments let to tourists and those let to residents.

The aim of this paper is to test the hypothesis of a segmentation of the housing market between tourists and residents. The paper also aims at identifying differences in the implicit prices for environmental characteristics, like landscape. Therefore a hedonic price function is estimated for the two anticipated surrogate submarkets and the derived implicit prices are compared. Incidentally, we also look for the presence of spatial segmentation. Since our sample is drawn from six Swiss alpine resorts, it is from six different geographic areas and possibly six submarkets.

The paper is organised into seven sections. Section 2 addresses the issue of market segmentation and its importance for the application of the hedonic price method from a theoretical, methodological and empirical perspective. Section 3 then reviews how landscape quality is dealt with in existing hedonic studies. Section 4 depicts the study area and the survey data. More specifically, it describes how two techniques developed in the context of multiple criteria decision analysis allow the construction of a variable measuring the landscape quality in the six Swiss alpine ski resorts where the survey was conducted. Subsequently, Section 5 uses this variable as one of the explanatories of the rent paid by tourists or by residents in the hedonic price functions. On the basis of the estimated functions, Section 6 examines the importance of market segmentation between tourists and residents and computes a hedonic price function controlling for market segmentation. Section 7 simulates rents paid by tourists and residents building on the hedonic price function developed in Section 6. Finally, Section 8 offers a brief discussion and concluding remarks. 


\section{Market Segmentation}

The early urban housing literature mentions the possible need to consider housing submarkets. However it was more convenient to assume a single market of homogeneous housing differentiated only by size. Identifying and characterising submarkets became more important notably with the emergence of the hedonic price technique. Since then a substantial literature has examined the phenomena. ${ }^{1}$

STRASZHeim (1975) is usually cited as having been the first to raise the issue of segmentation in the context of computing the hedonic price function for housing. He notes that "variation in housing characteristics and prices by location is a fundamental characteristic of the urban housing market" (p. 28). For him, an urban housing market may be segmented into a series of separate, compartmentalised submarkets due to either supply or demand-related factors. Thus the hedonic price function is likely to differ from one submarket to the next. On the supply side, submarkets may be differentiated by structure type (e.g. single-family detached, terraced house, town house, condominium), by structural characteristics (property age, equipment and fittings), or by neighbourhood characteristics (e.g. public education services, social factors, transportation). On the demand side, housing markets may be differentiated by household income and preferences. Wealthy households may be willing to pay more for housing. Households for whom housing has a higher relative marginal utility may also be willing to pay more. In turn, differences in willingness to pay triggers neighbourhood homogeneity.

As a result most hedonic studies use locational and political boundaries, or the demographic and socioeconomic characteristics of households such as race and income to differentiate between submarkets (Michaels and SMith, 1990). However questions remain as to what characteristics best differentiate submarkets, and how best to identify and measure these differences. An overly broad definition of a housing market would result in biased estimates due to an improperly aggregated sample (Linneman, 1980). Conversely, too narrow a definition would give rise to imprecise estimates because the estimates were not based on all available information (SCHAFFER, 1979).

As Freeman (1979, p. 163) summarises, two conditions must be met for different hedonic functions to exist in theory:

a) Buyers in one market segment ought not to participate significantly in another market segment. Thus some obstacles must prevent the mobility of purchasers

1 See Goodman and Thibodeau $(1998 ; 2003)$ for a large survey. 
across market segments. The obstacles could result from geography, discriminating practices, a lack of information, or a desire for ethnically and socioeconomically homogeneous neighbourhoods.

b) Either the structure of supply, the structure of demand, or both must differ across market segments. Either the characteristics of the housing stocks must vary or the buyers in separate segments must have different levels of income or different sets of preferences for housing.

If the first condition is met, but not the second, i.e. if buyers are immobile but both demand and supply structures are identical, then implicit prices will be similar. Conversely, buyers' perfect mobility and information will level differences in the implicit prices across market segments.

From a methodological perspective, analysts take different approaches to identifying submarkets and submarket boundaries. First, ad hoc approaches, often based on economic or geographical characteristics (e.g. using post codes or districts) have frequently been used to identify submarkets (Goodman, 1977). A second approach exploits factor analysis and statistical clustering techniques to assign properties to housing submarkets (DALE-Johnson, 1983; Bourassa, Hamelink, Hoesli and MacGregor, 1999). Designing hierarchical models for house prices using nested models is a third approach to identify the boundaries of housing submarkets (Goodman and Thibodeau, 1998).

From an empirical perspective, it is often difficult to test conclusively for market segmentation. Some methods are commonly employed to test the researcher's prior beliefs about segmentation. However the problem with most tests is that results indicative of market segmentation may be due to mis-specification of the hedonic price function, and not actual segmentation. Eventually researcher judgement remains, as in other instances, a guide for determining the market extent in a particular study (TAYLOR, 2003, pp.350-351).

Indeed the answer to the question 'what market segment should we analyse?' depends on what the researcher wants to gain from the analysis (Hidano, 2002, p. 51). The market should be chosen according to the amenity or according to the project to be valued. The different consumers of the amenity or users of the project must also be considered. 


\section{Landscape Quality and Hedonic Studies}

The seminal study about landscape valuation by Brush and Shafer (1975) already suggests that a consumer's evaluation of real estate overlooking a given natural scene correlates highly with the scene's predicted preference scores. NASAR (1983) also stressed that sight can be considered the most important sense in the immediate interaction with our surroundings.

Measuring the variable "landscape" or "landscape quality" is indeed a difficult issue. The hedonic studies investigating the impact of benefiting from a view (existence of a view) on housing price must be separated from those related to the aesthetic quality of the landscape.

Bourassa, Hoesli and Sun (2003) list only 35 hedonic studies measuring the implicit price of benefiting from a view over various sites (river, lake, ocean, mountains, forest, etc.). ${ }^{2}$ In most of these studies, the existence of a view impacts the house price in a positive way. Usually, this is minimally accounted for by means of a dummy variable (with or without a view). Traditional ways to collect data are in situ by visual observations and manually from maps or photographs. These methods are highly time-consuming and potentially biased. Some recent studies have taken advantage of geographic information systems to analyse topographic and remotely sensed land cover data (e.g. Powe, Garrod, Brunsdon and Willis, 1997; Salvi, Schellenbauer and Schmidt, 2004).

Attempts to model the impact of landscape quality on house prices are even less numerous (Li and Brown, 1980; Des Rosiers, Thérault, Kestens and Villeneuve, 2002). Bourassa, Hoesli and Sun (2003) introduced indicators to reflect the panoramic view over expanses of water for conurbations of the city of Auckland, New Zealand, as well as a series of variables measuring the average landscape and building quality in the neighbourhood. Benson, Hansen, Schwartz and Smersh (1998) or Schaerer, Baranzini, Ramirez and ThalMANN (2007) are examples of studies that examined the impact of different types and scope of the view on property values. All these studies confirm the difficulty of constructing explanatory variables that appropriately reflect the aesthetic quality of the landscape - i.e. that limit model specification problems and measurement errors (AtKInson and CROCKer, 1987).

2 See also Cavailhès, Brossard, Hilal, Joly, Tourneux, Tritz and Wavresky. (forthcoming). 


\section{Study Area and Survey Data}

The area of investigation consists of six selected alpine ski resorts, all located in the Swiss canton of Valais, namely Anzere, Champery, Grimentz, Haute-Nendaz, Ovronnaz, and Verbier. Several criteria were used to select this sample of resorts. The first criteria was to benefit from a clearly defined housing market, i.e. a market on which factors influencing the price can reasonably be expected to be the same. Second a large enough variability in the quality of the natural landscape and in the reputation between the resorts was needed. Finally, time limitations prevented the extension of the sample size beyond these six resorts.

Data for a sample of 510 apartments were collected, 403 of which were rented out to tourists and 107 were rented out to residents. The sample was drawn first with the help of local authorities and then of local real estate agents. The relative under-representation of the second category reflects the so-called "cold-bed syndrome". Most of the apartments in Swiss alpine ski resorts are let or sold to tourists, and as a result they tend to stay empty giving the impression that the resort itself is almost deserted during off-peak periods.

Real estate agents in each resort were first consulted in order to benefit from data relating to the structural characteristics of the buildings and apartments. We were thus able to collect 57 variables for each apartment in the sample (17 concerning the building and 40 for the apartment itself). Data from local tourist offices and authorities allowed us to establish 20 variables relating to local characteristics of the resorts. The characteristics of the neighbourhoods, or the distance separating the buildings from several "strategic" locations in the resort (ski lifts, resort centres and grocery stores), were surveyed with either GIS tools or fieldwork. All data refer to the situation as it existed during the 2002-03 winter season.

Collecting data to construct a variable reflecting the landscape quality required the application of specific methodologies. Two complementary techniques developed in the context of multiple criteria decision analysis were used. ${ }^{3}$

The silent negotiation technique was implemented first. This heuristic technique allows the reaching of a consensus within a group of people (Рістет and BOLLINGER, 2005). In our case, a group of "experts" was brought together for an evaluation session. The group included representatives from the tourism, ecology and tourism research sectors and public bodies. Members of the group were shown a series of photographs of the six natural landscapes to be valued, one

3 The methodology is discussed at length in Soguel, Tangerini and Pictet (2007). 
per resort. Each landscape was depicted using one panoramic photograph of the most prominent view from the resort. ${ }^{4}$ The participants were then requested to silently rank the photographs from the most to the least beautiful, with equal rankings allowed. Once the ranking was established, participants were asked to silently define the difference between the pairs of objects using a (ordinal) scale comprised of seven statements written on small cards, ranging from "no difference" to "an extreme difference" ("no difference", "very weak", "weak", "moderate", "strong", "very strong", and "extreme").

The MACBETH technique (Measuring Attractiveness by a Categorical Based Evaluation Technique) was then used to analyse statements provided by the silent negotiation. The algorithm of MACBETH calculates numerical values or scores that are compatible with the statements at our disposal (BANA E CostA and VANSNICK, 1999). These scores are established on a scale ranging from zero (the landscape deemed least attractive by the participants) to one hundred (the most attractive landscape). This offers us a variable that makes it possible to assess the qualitative gap between the beauty (or the aesthetic quality) of each natural landscape.

The computed scores for the natural landscape quality of each resort are as follows: Champery $=100$; Verbier $=75$; Ovronnaz $=56$; Grimentz $=44$; Anzere $=19$; Haute-Nendaz $=0$. Thus, Champery is seen as having the most attractive landscape in the sample (100) and Haute-Nendaz the least attractive (0). These resort-specific values are then combined with apartment-specific information in order to construct a variable reflecting not only the landscape quality but also the possibility of seeing the particular landscape quality from each apartment. Namely, the estimated landscape quality variable is conditional upon (a) the presence of a window on each façade of the apartment, (b) how well oriented the concerned façade is toward the measured landscape, and (c) the fact that there might be an obstacle in front of the façade that prevents the view from being seen. ${ }^{6}$ Eventually, this variable reflects the visibility-adjusted quality of the landscape.

4 The photographs were not selected randomly. Photographs were taken after consultations with estate agents and/or members of the tourism offices in each location. Photographs can be seen at www.idheap.ch/idheap.nsf/go/landscape.

5 French was used in the group with differences defined as "nulle", "très faible", "faible", "modérée", "forte", "très forte" and "extrême".

6 Landscape $_{i r}=\left(\right.$ quality $\left._{r}+10\right)$ if (window $\mathrm{A}_{i}>0$ and orientation $\mathrm{A}_{i}>3$ and obstacle $\left.\mathrm{A}_{i}>0\right)$ or (windows $\mathrm{B}_{i}>0$ and orientation $\mathrm{B}_{i}>3$ and obstacle $\mathrm{B}_{i}>0$ ) or (window $\mathrm{C}_{i}>0$ and orientation $\mathrm{C}_{i}>3$ and obstacle $\mathrm{C}_{i}>0$ ) or (window $\mathrm{D}_{i}>0$ and orientation $\mathrm{D}_{i}>3$ and obstacle $\mathrm{D}_{i}>0$ 


\section{Model Specification and Results}

The hedonic price function is specified empirically in the same way for tourists and for residents:

$$
H_{i}=H\left(S_{i}, N_{i}, L_{i}\right)
$$

Where $H_{i}$ is the gross monthly rent in Swiss francs (CHF), including bills, paid for apartment $i, S_{i}$ represents the vectors of the structural characteristics of the apartment and of the house in which the apartment is located. $N_{i}$ denotes the local neighbourhoods' characteristics (e.g. resort's infrastructure or ski-runs), and $L_{i}$ is the quality of the landscape conditional upon its visibility.

The theory gives few insights into the correct specification of the functional form of the hedonic price equation, although it affects implicit prices. Therefore, various models were estimated using the general transformation proposed by Box and Cox (1964) in order to determine the functional form that maximises the likelihood (MLE) of the hedonic function? ${ }^{7}$ The Box-Cox procedure suggests that a transformation is not necessarily needed. However the restricted $\log$-likelihood also indicates that a logarithmical transformation on both sides is more efficient than the linear specification. Following this finding, and also to allow for a more intuitive interpretation and to compare coefficients between our models, we retain the log-log transformation.

We apply two usual additional cumulative criteria to select explanatory variables: (a) the variable presents the theoretically expected sign or the sign identified

where landscape is the conditional landscape quality for apartment $i$ in resort $r$ (i.e. provided that one can access the landscape from the apartment); quality is the MACBETH index of landscape quality in resort $r$; window $\mathrm{A}_{i}$ to window $\mathrm{D}_{i}$ are the existence of windows on each $\mathrm{A}$ to $\mathrm{D}$ façade; orientation $\mathrm{A}_{i}$ to orientation $\mathrm{D}_{i}$ are indices of how good each façade's orientation is toward the considered landscape $(1=$ poor; $5=$ excellent $)$; obstacle $\mathrm{A}_{i}$ to $\mathrm{D}_{i}$ is a dummy indicating if an obstacle prevents $(=0)$ or not $(=1)$ the view to be seen. The value of 10 is arbitrarily chosen and is then added to the MACBETH index when there is a window on a given façade, when the orientation of the considered façade is at least good $(\geq 4)$ and when there is no obstacle. As a result, when the landscape is accessible, the conditional MACBETH score is as follows : Champery $=110$; Verbier $=85$; Ovronnaz $=66$; Grimentz $=54$; Anzere $=29$; Haute-Nendaz $=10$.

7 The general transformation of the dependent or independent variable $H_{i}(>0)$ is the following: $H_{i}^{(\lambda)}=\left(H_{i}^{\lambda}-1\right) / \lambda$, where $\lambda$ is a Box-Cox parameter determined to normalise the error distribution. The transformation allows a great deal of flexibility in the search for an appropriate functional form. The transformation of the variable can possibly be linear $(\lambda=1)$ or a natural logarithm $(\lambda=0)$. 
in several previous studies; (b) the variable is most often significant in the tested models.

The gap between the rent paid by tourists on the one hand and by residents on the other justifies that these two submarkets are modelled separately. As depicted in Table 1 the sample average monthly rent per room paid by a tourist is 1800 $\mathrm{CHF}$, compared to 420 in the case of a resident.

Table 1: Average Nominal Monthly Rent per Room in the Six Considered Swiss Alpine Ski Resorts, by Decreasing Magnitude of the Mean in the Case of Tourist Apartments

\begin{tabular}{|c|c|c|c|c|c|c|c|c|c|c|}
\hline & \multicolumn{5}{|c|}{ Tourists' apartment } & \multicolumn{5}{|c|}{ Residents' apartment } \\
\hline & $\mathrm{N}$ & Mean & Std.D. & Min & Max & $\mathrm{N}$ & Mean & Std.D. & Min & $\operatorname{Max}$ \\
\hline Verbier & 49 & 2596 & 563 & 1375 & 4520 & 40 & 465 & 91 & 323 & 725 \\
\hline Anzere & 65 & 2011 & 497 & 980 & 3220 & 19 & 371 & 134 & 240 & 650 \\
\hline Ovronnaz & 59 & 1934 & 693 & 952 & 4360 & 18 & 399 & 115 & 283 & 550 \\
\hline Haute-Nendaz & 65 & 1593 & 497 & 913 & 2868 & 11 & 403 & 85 & 257 & 600 \\
\hline Grimentz & 83 & 1586 & 397 & 1028 & 3008 & 10 & 319 & 55 & 263 & 400 \\
\hline Champery & 80 & 1433 & 360 & 950 & 2600 & 7 & 523 & 147 & 275 & 670 \\
\hline Overall & 401 & 1800 & 613 & 913 & 4520 & 105 & 420 & 117 & 240 & 725 \\
\hline
\end{tabular}

Table 1 also indicates substantial differences between resorts. The tourists' sample average rent per room (without kitchen, kitchen corner, bathroom, or toilets) is 2596 CHF in Verbier, almost double compared to Champery (1433). However, smaller differences in averages also appear for residents (maximum of $523 \mathrm{CHF}$ in Champery and minimum of 319 in Grimentz). The relatively small size of sub-samples in each resort, especially in the case of residents (e.g. $N=7$ in Champery), prevents us from modelling the rental market at the resort level. To nevertheless display how the spatial segmentation between the six considered resorts affects the results, two modelling strategies are used. The first strategy utilises one single variable for the number of rooms (lnRooms) $\left(S_{i}\right.$ variable) and relies on the local neighbourhoods' characteristics $\left(N_{i}\right)$ to control for the difference in rents between resorts. The second strategy, in addition to utilising local neighbourhood characteristics $\left(N_{i}\right)$, controls for this difference by interacting the number of rooms with a dummy variable for each 
resort (e.g. $\ln$ Rooms $\times$ Verbier) resulting in strictly positive values when flats are located in Verbier (Verbier $=1)$ and null values when flats are located elsewhere $(\text { Verbier }=0)^{8}$.

Hence, the results for four models are presented in Table 2: two for tourists and two for residents. Breusch-Pagan, Cook-Weisberg and Szroeter tests signal heteroscedasticity problems especially when modelling without spatially segmenting the number of rooms and modelling the market for residents. Therefore we use the Huber-White-sandwich estimator of the variance of the regression estimators.

Table 2: Hedonic Price Functions for Apartments Rented either by Tourists or by Residents in Six Swiss Alpine Resorts (OLS, log-log Specification) ${ }^{a}$

\begin{tabular}{|c|c|c|}
\hline \multirow[t]{3}{*}{ Independent variables } & \multicolumn{2}{|c|}{ Models } \\
\hline & Tourists & Residents \\
\hline & 2 & 3 \\
\hline $\begin{array}{l}\text { Ln Rooms (number of rooms in the apartment } \\
\text { excluding kitchen and bathrooms) }\end{array}$ & $\begin{array}{l}0.5748^{* *} \\
(21.73)\end{array}$ & $\begin{array}{l}0.5190^{* *} \\
(14.56)\end{array}$ \\
\hline $\begin{array}{l}\text { Ln Rooms } \times \text { Verbier (number of rooms in the } \\
\text { apartment if located in Verbier) }\end{array}$ & $\begin{array}{l}0.9036^{* *} \\
(15.17)\end{array}$ & $\begin{array}{l}0.6100^{* *} \\
(7.87)\end{array}$ \\
\hline Ln Rooms $\times$ Anzere & $\begin{array}{l}0.6507^{* *} \\
(15.17)\end{array}$ & $\begin{array}{l}0.4445^{* *} \\
(12.62)\end{array}$ \\
\hline Ln Rooms $\times$ Ovronnaz & $\begin{array}{l}0.5234^{* *} \\
(9.50)\end{array}$ & $\begin{array}{l}0.5264^{* *} \\
(9.83)\end{array}$ \\
\hline Ln Rooms $\times$ Champery & $\begin{array}{l}0.5178^{* *} \\
(12.88)\end{array}$ & $\begin{array}{l}0.4082^{* *} \\
(8.22)\end{array}$ \\
\hline Ln Rooms $\times$ Grimentz & $\begin{array}{l}0.4813^{* *} \\
(12.54)\end{array}$ & $\begin{array}{l}0.5168^{* *} \\
(14.46)\end{array}$ \\
\hline
\end{tabular}

8 Another strategy to cope with the differences between resorts consists of introducing in the model a dummy variable for each resort. Results for this strategy are not reported for two reasons. First, it leads to identical conclusions: the impact of the landscape quality is similar and so is the finding about the segmentation between residents and tourists as well as the spatial segmentation. Second, this strategy comes at the cost of having to abandon all other local neigbourhood characteristics $N_{i}$ since these variables do not vary within the resorts and are thus colinear with the resort-specific dummies. It also offers less explanatory power than the models where the number of rooms interacts with a dummy for each resort (see Models 2 and 4). 


\begin{tabular}{|c|c|c|c|c|}
\hline \multirow[t]{3}{*}{ Independent variables } & \multicolumn{4}{|c|}{ Models } \\
\hline & \multicolumn{2}{|c|}{ Tourists } & \multicolumn{2}{|c|}{ Residents } \\
\hline & 1 & 2 & 3 & 4 \\
\hline Ln Rooms $\times$ Haute-Nendaz & & $\begin{array}{l}0.4209^{* *} \\
(9.91)\end{array}$ & & $\begin{array}{l}0.4182^{* *} \\
(4.80)\end{array}$ \\
\hline $\begin{array}{l}\text { Ln Landscape-Quality (visibility-adjusted } \\
\text { MACBETH score) }\end{array}$ & $\begin{array}{l}0.0449^{* *} \\
(6.57)\end{array}$ & $\begin{array}{l}0.0225^{* *} \\
(3.84)\end{array}$ & $\begin{array}{l}0.0351^{* *} \\
(4.28)\end{array}$ & $\begin{array}{l}0.0287^{* *} \\
(2.67)\end{array}$ \\
\hline Ln Resort-Infrastructure ${ }^{b}$ & $\begin{array}{l}0.1297^{* *} \\
(6.19)\end{array}$ & $\begin{array}{l}-0.0260 \\
(-0.54)\end{array}$ & $\begin{array}{l}0.1962 \\
(0.82)\end{array}$ & $\begin{array}{l}0.0156 \\
(0.58)\end{array}$ \\
\hline $\begin{array}{l}\text { Ln Distances-to-Infrastructure (sum of the } \\
\text { distances to the resort's main infrastructures: } \\
\text { ropeways, grocery stores, and resort centres) }\end{array}$ & $\begin{array}{l}0.0428^{* *} \\
(2.68)\end{array}$ & $\begin{array}{l}0.0001 \\
(0.01)\end{array}$ & $\begin{array}{l}0.1393^{* *} \\
(2.63)\end{array}$ & $\begin{array}{l}0.1509^{* *} \\
(2.91)\end{array}$ \\
\hline $\begin{array}{l}\text { Ln Average-Ski-Runs (ratio between the } \\
\text { length of the runs in kilometres and the } \\
\text { number of ski lifts) }{ }^{c}\end{array}$ & $\begin{array}{l}0.3234^{* *} \\
(10.45)\end{array}$ & $\begin{array}{l}0.1678^{*} \\
(2.40)\end{array}$ & $\begin{array}{l}-0.0380 \\
(-0.53)\end{array}$ & $\begin{array}{l}-0.1663^{*} \\
(-2.22)\end{array}$ \\
\hline $\begin{array}{l}\text { Ln Flat-Equipment (1+sum of dummies if the } \\
\text { flat features a TV-cable, fire-place, balcony, } \\
\text { dishwasher, security system) }\end{array}$ & $\begin{array}{l}0.1545^{* *} \\
(3.32)\end{array}$ & $\begin{array}{l}0.1914^{* *} \\
(4.44)\end{array}$ & $\begin{array}{l}0.1027^{* *} \\
(2.75)\end{array}$ & $\begin{array}{l}0.1091^{*} \\
(2.15)\end{array}$ \\
\hline Constant & $\begin{array}{l}7.3369^{* *} \\
(92.10)\end{array}$ & $\begin{array}{l}7.2409^{* *} \\
(52.94)\end{array}$ & $\begin{array}{l}6.1568^{* *} \\
(38.02)\end{array}$ & $\begin{array}{l}6.3375^{* *} \\
(42.43)\end{array}$ \\
\hline $\mathrm{N}$ & 401 & 401 & 105 & 105 \\
\hline Adjusted- $\mathrm{R}^{2}$ & 0.7472 & 0.8151 & 0.8517 & 0.8677 \\
\hline $\mathrm{F}$ & 202.56 & 187.30 & 91.15 & 80.91 \\
\hline Largest VIF & 1.38 & 6.93 & 2.43 & 4.36 \\
\hline Mean VIF & 1.25 & 3.33 & 1.98 & 2.62 \\
\hline$\sigma^{2}(\mathrm{OLS})$ & 0.22 & 0.19 & 0.15 & 0.15 \\
\hline
\end{tabular}

a. The dependent variable is the natural logarithm of the rent during the period of February to March 2003 (including bills). For residents, the average nominal monthly rent equals $812 \mathrm{CHF}$, with a standard deviation of 308 . For tourists, the average nominal rent on a monthly basis equals $4635 \mathrm{CHF}$, with a standard deviation of 2301. In March 2003, $1 \mathrm{CHF}=0.681 €$.

$T$-values are shown between parentheses under the estimated parameters according to HuberWhite-sandwich estimator of the variance of the regression estimators. Coefficients with double asterisk are significant to $99 \%$. Those with a single asterisk are significant to $95 \%$ (bilateral test).

b. The infrastructure index is made up of several sub-indexes. Each of them measures the importance of a type of infrastructure relative to the total offered by the six resorts. For example, Verbier hosts 13 (34\%) of the 38 bars of the six resorts (100\%) and 18 (46\%) of the sports stores. After averaging the percentages over the seven different types of infrastructure, Verbier offers the largest total infrastructure (37\%), and Grimetz and Ovronnaz the smallest (7\% each).

c. This average length offers an estimate of the "rate-of-return" one can expect from each lift, in terms of the duration of the descent. 
There is no indication of multicollinearity, according to the variance inflation factors (the largest and mean VIF peaks at a value of 6.93 and 3.33 which is far from the generally accepted threshold of 10).

The independent variables retained in the hedonic function explain a share of the rent variability ranging between 0.75 (Model 1) and 0.87 (Model 4). However the set of independent variables that influence significantly and with the expected sign both tourists' and residents' rent is rather small. ${ }^{9}$

As in many hedonic price studies, the number of rooms (Ln Rooms) influences positively and significantly both tourists' and residents' rent. It is true in both types of models: with or without interaction between the number of rooms and a dummy variable for each resort (Models 4 and 2, respectively 3 and 1). However, according to the size of the coefficient, the effect is larger on the tourist market.

It is interesting to see that interacting the number of rooms with a dummy for each resort captures the effect of local neighbourhood characteristics like the visibility-adjusted quality of the landscape (Ln Landscape-Quality), the resorts infrastructure (Ln Resort-Infrastructure), the distance to infrastructure (Ln Distancesto-Infrastructure) and the average length of the ski runs (Ln Average-Ski-Runs). In fact, these latter characteristics are able to significantly explain the variability of the rents especially in Model 1 (model for tourists). However the value of their coefficients obviously drops when one introduces interaction variables for the number of rooms into the model, as does their degree of significance. This demonstrates that the local neighbourhood characteristics at our disposal are not powerful enough to explain fully the variability of the rents between the six considered resorts. Therefore, Model 1 still suffers to some extent from a spatial segmentation bias.

Although the statistics for the visibility-adjusted quality of the landscape are affected when moving from Model 1 to Model 2 or from Model 3 to Model 4, they nevertheless convey that the quality of landscape impacts significantly and positively on the rents.

The distance to a resort's main infrastructure influences the rents with a substantial probability, except in Model 2. Interestingly, it impacts positively, meaning that rents are relatively higher for apartments located away from the resorts'

9 Several additional variables were tested and rejected in light of the criteria used to select the variables to be retained in the models. Just to mention a few, they include the quality of the built environment in the resort (MACBETH score), the level of noise pollution, the age of the house, the number of years since the last repair either in the house or in the apartment, the number of apartments in the house, and the floor on which the apartment is located. 
main infrastructure. This finding contradicts some existing studies, admittedly mostly conducted in urban areas, including in Switzerland, where housing prices are negatively correlated with distance from infrastructure (e.g. Grosclaude and Soguel, 1992). However, in their synthesis of 125 US hedonic studies, SIRmans, MacPherson and Zietz (2005) found that there were as many studies showing a significant negative relationship between housing prices and distance to the city centre ( 5 among the listed studies) as ones finding a significant positive relationship ( 5 studies). ${ }^{10}$

The extent to which an apartment has facilities (e.g. cable television, fire-place, balcony, dishwasher, security systems) is shown to positively and significantly influence the rent in most cases.

At this point, differences between the two groups can also be stressed. Both the resort's infrastructure and the average length of the ski runs significantly, positively and markedly affect tourists' rent (though the former variable turns out insignificant in Model 2). However, they have no significant effect on residents' rent (with even the wrong expected sign in the case of the ski runs' average length). The interpretation is that residents either do not use these facilities or they are more able than tourists to use substitute sites.

As always, the log-log specification offers a straight interpretation of the estimated parameters. For example, doubling the number of rooms increases the tourists' rent by about $57 \%$ (Model 1) and the residents' by about 24\% (Model 2). This is consistent with previous findings pointing to economies of scale in order to explain that the rents do not double (e.g. no need for an additional kitchen). However, the two models that use geographic interaction terms to allow for different elasticities indicate that the effect is larger in Verbier $(90 \%$ increase in tourists' rent - Model 2 - and 61\% in residents' - Model 4) and lower elsewhere (e.g. $42 \%$ increase in Haute-Nendaz for both tourists and residents). Doubling the MACBETH score for the visibility-adjusted quality of the landscape triggers a rent increase of about 2\% for tourists (Model 2) and 3\% for residents (Model 4).

10 In five additional studies the variable is insignificant. 


\section{Market Segmentation between Tourists and Residents}

From a theoretical point of view, and according to the conditions summarised by FrEemAN (1979), the housing market in ski resorts appears clearly segmented between tourists and residents. Indeed tourist tenants do not participate in the residents' market segment, and vice-versa. There are several reasons for this lack of mobility. One of them is probably the discriminating practices of estate and travel agencies toward the two categories of clients. The structure of supply and the structure of demand obviously are different across the two segments. As for supply-related factors, tourists' apartments are let fully furnished on a weekly basis with bid rents varying seasonally for a time-limited tenancy. On the contrary, residents' apartments are let unfurnished on a monthly basis with invariable bid rents for a usually unlimited tenancy. Tourists may have a larger budget allowance for housing than residents. For that reason the demand structure is quite different, although preferences do not contrast that much according to the empirical evidence provided by the two samples. For instance, the number of rooms is 2.7 on average in tourists' apartments and 2.2 in residents' and the average equipment index amounts to 4.0 and 3.1 respectively.

From an empirical perspective, Allen, Springer and Waller (1995) suggest comparing the regression equations for each submarket using a Chow test. The Chow test identifies a possible difference between equations under the null hypothesis that all of the parameters (including the constant) in the two models are equivalent. Table 3 displays computed and critical F-values in order to compare the structure of the tourists' model to the one of residents'. Thus Model 1 to Model 3 (models without geographic interaction terms for the number of rooms) and Model 2 to Model 4 (models with spatially segmented variables) are compared. Both comparisons indicate that the computed F-value is far greater than the critical value. Therefore, it is possible to strongly reject the hypothesis of equivalence of hedonic price functions.

An important prescription when applying the Chow test is that the disturbance variance is the same across models. The estimates of $\sigma^{2}$ in Table 2 indicate that this assumption is unlikely to be perfectly true: the disturbance variance from the tourists' models (and especially Model 1) is larger than that for the residents' models. A simple Wald test can be used alternatively to the Chow test. Since our samples are reasonably large, the test is valid whether or not disturbance variances are the same. Again computed values exceed the critical values allowing us to strongly reject the null hypothesis of models having a similar structure. These results support the assumption that the two samples represent apartments being traded in distinct submarkets. 
Table 3: Results of Tests for Differences between Tourists' and Residents' Hedonic Functions ${ }^{\mathrm{a}}$

\begin{tabular}{lcc}
\hline Comparison of models ... & $\begin{array}{c}\text {.. without geographical } \\
\text { interaction terms } \\
\text { (Models 1 and 3) }\end{array}$ & $\begin{array}{c}\text {.. with geographical } \\
\text { interaction terms } \\
\text { (Models 2 and 4) }\end{array}$ \\
\hline Chow test F-statistics & $547.69^{* *}$ & $401.49^{* *}$ \\
Wald test Chi-squared statistics & $8047.6314^{* *}$ & $12789.516^{* *}$ \\
Tiao-Goldberger test F-statistics & 0.66 & \\
Ln Rooms & & $11.89^{* *}$ \\
Ln Rooms $\times$ Verbier & & $10.29^{* *}$ \\
Ln Rooms $\times$ Anzere & & 0.02 \\
Ln Rooms $\times$ Ovronnaz & & 0.62 \\
Ln Rooms $\times$ Champery & 1.29 & 0.00 \\
Ln Rooms $\times$ Grimentz & 1.08 & 0.02 \\
Ln Rooms $\times$ Haute-Nendaz & 1.53 & 0.38 \\
Ln Landscape-Quality & $18.32^{* *}$ & 0.06 \\
Ln Resort-Infrastructure & 0.48 & $4.39^{*}$ \\
Ln Distances-to-Infrastructure & $309.97^{* *}$ & $4.26^{*}$ \\
Ln Average-Ski-Runs & 506 & 0.12 \\
Ln Flat-Equipment & & $13.94^{* *}$ \\
Constant & & 506 \\
\hline $\mathrm{N}$ & & \\
\hline
\end{tabular}

a Coefficients with double asterisks are different at the $99 \%$ level between the compared models, those with a single asterisk at the $95 \%$ level.

An important consequence of the existence of submarkets is that estimates of implicit prices derived from the parameters of a pooled data hedonic function are likely to be biased. To compare the parameters across submarkets we employ the Tiao-Goldberger test suggested by Michaels and SMith (1990). In our case the test is particularly useful since it considers the null hypothesis that the coefficients of a particular regressor take the same value in each of the models. The test works by comparing each parameter estimate to the weighted sum of parameter estimates across Models 1 and 3 as well as across Models 2 and 4. Table 3 reports the parameter estimates and the Tiao-Goldberger test statistics for the 
coefficients that were estimated across the two submarkets. Of most interest in this research is the possible difference in the implicit price of the landscape quality. The test statistics for both comparisons indicate that the null hypothesis of equality of parameter estimates cannot be rejected, even at the $1 \%$ level of confidence. This finding is important and shows that the quality of the landscape does not affect the rental markets of tourists and residents in different ways. In turn the null hypothesis can be rejected for some other parameters (test scores italicised). Models with geographical interaction terms are different as far as five coefficients are concerned, including the constant.

This finding leads us to adapt the estimation strategy and to compute the two more general models presented in Table 4. Each model is a joint model for both tourists and residents. When the Tiao-Goldberger test indicates that the parameters are different between the two markets the concerned explanatory variable is interacted either with a dummy indicating that the tenant is a resident $(\mathrm{R})$ or with a dummy indicating the tenant is a tourist $(\mathrm{T})$. Model 5 presents results without geographic interaction terms for the number of rooms and Model 6 presents results with geographic interaction terms.

This further modelling step has three consequences. First, it sheds further light on the differences in parameters and their impact on rents. For example, the difference between constants in tourists' and residents' models is approximately equal to 1 (7.33-6.29 in Model 5 and 7.31 - 6.13 in Model 6). The significance of the parameters echoes the one found in Models 1 to 4 . Second, it provides us with more accurate estimates for parameters that are common to both tourists and residents. The 95\%-confidence intervals for the landscape quality variable show clearly the increased accuracy. Intervals are broader in Model 2 (0.0110 to 0.0340) and Model 4 (0.0074 to 0.0501) than in Model 6 (0.0157 to 0.0341). Third, since Models 5 and 6 are general and no longer specific to either tourists or residents, the estimated hedonic functions explain a slightly lower share of the rent variance than the previous - specific - models. Considering models with geographic interaction terms for the number of rooms, the adjusted- $\mathrm{R}^{2}$ is slightly lower in Model $6(0.8087)$ than in Model $2(0.8151)$ for tourists. It is also slightly lower in Model 6 (0.8587) than in Model 4 (0.8677) for residents. 
Table 4: Joint Hedonic Price Functions for Apartments Rented by Tourists and by Residents in Six Swiss Alpine Resorts (OLS, log-log Specification)

\begin{tabular}{|c|c|c|c|c|}
\hline \multirow[t]{2}{*}{ Independent variables } & \multicolumn{2}{|c|}{$\begin{array}{l}\text { Model 5, without } \\
\text { geographical } \\
\text { interaction terms }{ }^{a}\end{array}$} & \multicolumn{2}{|c|}{$\begin{array}{l}\text { Model 6, with } \\
\text { geographical } \\
\text { interaction terms }\end{array}$} \\
\hline & Parameters & T-values & Parameters & T-values \\
\hline Ln Rooms & $0.5770^{* *}$ & 25.76 & & \\
\hline Ln Rooms $\times$ Verbier $\times$ R & & & $0.5995^{* *}$ & 10.66 \\
\hline Ln Rooms $\times$ Verbier $\times \mathrm{T}$ & & & $0.8857^{* *}$ & 20.46 \\
\hline Ln Rooms $\times$ Anzere $\times \mathrm{R}$ & & & $0.4432^{* *}$ & 16.66 \\
\hline Ln Rooms $\times$ Anzere $\times \mathrm{T}$ & & & $0.6499^{* *}$ & 16.03 \\
\hline Ln Rooms $\times$ Ovronnaz & & & $0.5267^{* *}$ & 12.55 \\
\hline Ln Rooms $\times$ Champery & & & $0.5102^{* *}$ & 14.11 \\
\hline Ln Rooms $\times$ Grimentz & & & $0.4905^{* *}$ & 15.77 \\
\hline Ln Rooms $\times$ Haute-Nendaz & & & $0.4122^{* *}$ & 11.5 \\
\hline Ln Landscape-Quality & $0.0417^{* *}$ & 7.58 & $0.0249^{* *}$ & 5.31 \\
\hline Ln Resort-Infrastructure ${ }^{\mathrm{b}}$ & $0.1138^{* *}$ & 6.39 & -0.0060 & -0.19 \\
\hline Ln Distances-to-Infrastructure & $0.0470^{* *}$ & 3.11 & & \\
\hline Ln Distances $\times \mathrm{R}$ & & & $0.1320^{* *}$ & 2.69 \\
\hline Ln Distances $\times \mathrm{T}$ & & & 0.0020 & 0.13 \\
\hline Ln Average-Ski-Runs $\times \mathrm{R}$ & -0.0592 & -1.01 & -0.0777 & -1.19 \\
\hline Ln Average-Ski-Runs $\times \mathrm{T}$ & $0.3251^{* *}$ & 10.89 & $0.1695^{* *}$ & 2.72 \\
\hline Ln Flat-Equipment & $0.1324^{* *}$ & 3.93 & $0.1672^{* *}$ & 5.26 \\
\hline Constant $\times \mathrm{R}$ & $6.2926^{* *}$ & 56.28 & $6.1325^{* *}$ & 46.96 \\
\hline Constant $\times \mathrm{T}$ & $7.3389^{* *}$ & 110.51 & $7.3079^{* *}$ & 66.12 \\
\hline 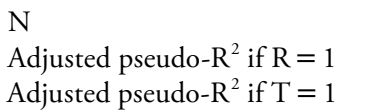 & $\begin{array}{l}506 \\
0.8270 \\
0.7422\end{array}$ & & $\begin{array}{r}506 \\
0.8587 \\
0.8087\end{array}$ & \\
\hline
\end{tabular}

a Same dependent variable as in Models 1 and 3.

b Same dependent variable as in Models 2 and 4.

$\mathrm{R}$ Dummy variable taking the value 1 if the tenant is a resident, 0 if a tourist.

$\mathrm{T}$ Dummy variable taking the value 1 if the tenant is a tourist, 0 if a resident.

Coefficients with double asterisk are significant to $99 \%$. Those with a single asterisk are significant to $95 \%$ (bilateral test). T-values according to Huber-White-sandwich estimator of the variance of the regression estimators. 


\section{Simulating the Impact of Changes in Landscape Quality}

Table 5 presents the simulated rent according to the visibility-adjusted quality of the landscape in each resort. All other characteristics of the apartment $\left(S_{i}, N_{i}\right)$ are held constant at their average value. Simulations are carried out for rents paid by tourists (upper part of the table) or by residents (lower part of the table) using either models with or without geographic interaction terms for the number of rooms (Model 6 and Model 5). When the simulation is based on Model 6 (i.e. with interaction terms), two extremes are considered: an apartment specifically located in Verbier vs. one in Champery (i.e. interaction variables for resorts other than the considered one being set equal to 0 ). Therefore the results reported in the column "Verbier" are for an average flat located in Verbier and rented by a tourist (upper part of the column) or a resident (lower part) that benefits from a landscape quality varying between 10 and 110 according to the visibility-adjusted MACBETH score. Results reported in the column "Haute-Nendaz" are for a flat located in this resort, rented either by a tourist or a resident and benefiting from varying levels of landscape quality.

Considering the two extreme visibility-adjusted MACBETH scores for the landscape quality, the rent for a score of 110 (as in Champery) is considerably higher than for a score of 10 (as in Haute-Nendaz). Comparison between the simulations using both models also shows differences. Simulations with Model 5 indicate a percentage of variation due to landscape quality almost twice as high as the one with Model 6 (21.6\% and $12.4 \%$ respectively. Since both models are joint models for tourists and residents, the percentage of variation in the rent is the same across the two groups. This underscores the assertion that the relative marginal implicit price of landscape quality is identical.

However, when it comes to the nominal marginal implicit price (measured in $\mathrm{CHF}$ ), the double-log specification of the hedonic equations must be taken into consideration. Due to the multiplicative property of such a specification ${ }^{11}$, a "boosting" and multiplicative effect appears as the constant differs across the two groups. Since the difference in constant is 1.05 in Model 5 and 1.18 in Model 6, a multiplicative effect of 2.85 (Model 5) and 3.24 (Model 6) occurs on the nominal tourists' market price when the visibility-adjusted quality of the landscape varies (or any other characteristic). Were the landscape quality variable to double, then the effect would be an increase in rent of $4.17 \%$ according to Model 5 and of $2.49 \%$ according to Model 6 . However the nominal effect measured in CHF

$11 \ln Y=\ln a+b_{1} \ln X_{1}+b_{2} \ln X_{2}+\ldots+b_{n} \ln X_{n}$, hence $Y=a X_{1}^{b_{1}} X_{2}^{b_{2}} \ldots X_{n}^{b_{n}}$. 
Table 5: Simulated Monthly Rents for an Apartment when the Visibility-Adjusted Quality of the Landscape Varies, Holding Average Characteristics Constant, According to Model 5 and Model 6 Depending on whether the Tenant is a Tourist or a Resident ${ }^{\mathrm{a}}$

Apartments rented by tourists $(T=1, R=0)$

\begin{tabular}{lcccccc}
\hline $\begin{array}{l}\text { Landscape quality } \\
\text { (visibility-adjusted }\end{array}$ & \multicolumn{2}{c}{ Model 5 } & \multicolumn{5}{c}{ Model 6 $^{\text {Verbier }}{ }^{\mathrm{c}}$} & \multicolumn{3}{c}{ Haute-Nendaz $^{\mathrm{d}}$} \\
$\begin{array}{l}\text { MACBETH score } \\
\text { in each resort) }\end{array}$ & $\begin{array}{c}\text { Rent } \\
\text { in CHF }\end{array}$ & $\Delta \%^{\mathrm{b}}$ & $\begin{array}{c}\text { Rent in } \\
\text { CHF }\end{array}$ & $\Delta \%^{\mathrm{b}}$ & $\begin{array}{c}\text { Rent } \\
\text { in CHF }\end{array}$ & $\Delta \%^{\mathrm{b}}$ \\
\hline 110 (Champery) & 4980 & 10.5 & 6208 & 6.1 & 3934 & 6.1 \\
85 (Verbier) & 4926 & 9.3 & 6168 & 5.5 & 3906 & 5.5 \\
66 (Ovronnaz) & 4875 & 8.2 & 6130 & 4.8 & 3878 & 4.8 \\
54 (Grimentz) & 4834 & 7.3 & 6099 & 4.3 & 3855 & 4.3 \\
29 (Anzere) & 4711 & 4.5 & 6006 & 2.7 & 3775 & 2.7 \\
10 (Haute-Nendaz) & 4507 & 0.0 & 5849 & 0.0 & 3715 & 0.0 \\
\hline
\end{tabular}

Apartments rented by residents $(T=0, R=1)$

\begin{tabular}{lcccccc}
\hline $\begin{array}{l}\text { Landscape quality } \\
\text { (visibility-adjusted }\end{array}$ & \multicolumn{2}{c}{ Model 5 } & \multicolumn{5}{c}{ Model 6 } \\
$\begin{array}{l}\text { MACBETH score } \\
\text { in each resort) }\end{array}$ & $\begin{array}{c}\text { Rent } \\
\text { in CHF }\end{array}$ & $\Delta \%^{\mathrm{b}}$ & $\begin{array}{c}\text { Rent } \\
\text { in CHF }\end{array}$ & $\Delta \%^{\mathrm{b}}$ & $\begin{array}{c}\text { Rent } \\
\text { in CHF }\end{array}$ & $\Delta \%^{\mathrm{b}}$ \\
\hline 110 (Champery) & 1054 & 10.5 & 1119 & 6.1 & 935 & 6.1 \\
85 (Verbier) & 1042 & 9.3 & 1112 & 5.5 & 929 & 5.5 \\
66 (Ovronnaz) & 1032 & 8.2 & 1105 & 4.8 & 923 & 4.8 \\
54 (Grimentz) & 1023 & 7.3 & 1099 & 4.3 & 919 & 4.3 \\
29 (Anzere) & 997 & 4.5 & 1083 & 2.7 & 905 & 2.7 \\
10 (Haute-Nendaz) & 954 & 0.0 & 1054 & 0.0 & 881 & 0.0 \\
\hline
\end{tabular}

a The sample average characteristics are: Rooms $=2.6$; Resort-infrastructure $=16.7 \%$; Distanceto-infrastructure $=1.6 \mathrm{~km}$; Average-ski-runs $=3.7 \mathrm{~km}$; Flat-equipment $=3.8$

$\mathrm{b}$ The baseline is the lowest visibility-adjusted MACBETH score when the landscape quality is accessible (10 for Haute-Nendaz).

c Simulation as if the apartment were specifically located in Verbier.

$\mathrm{d}$ Simulation as if the apartment were located specifically in Haute-Nendaz. 
is still 2.85 (Model 5) and 3.24 (Model 6) times higher for tourists than for residents, all other things being equal. ${ }^{12}$

Therefore, although the marginal implicit price can be considered identical at the level of the concerned parameter in the two markets in relative terms, it is not the case when considering the nominal variation of the rent. In this case, one must consider the multiplicative effects among the variables and the parameters included in the model.

According to Model 6, the simulated rent is much higher if the apartment is hypothesised to be located in Verbier rather than in Haute-Nendaz, reflecting the difference in the value of the parameters.

\section{Discussion and Conclusion}

The aim of the paper was to test the hypothesis of segmentation of the housing market between tourists and residents. It was also to identify differences in the implicit prices for landscape. Therefore one specific hedonic price function was computed for the rent paid by tourists and another function was estimated for the rent paid by residents. As our sample is drawn from six Swiss alpine resorts we were also able to look for a possible spatial segmentation.

The estimated hedonic price functions show that the local neighbourhood variables at our disposal (resort infrastructure, distance to the infrastructure, average length of the ski runs, quality of the landscape) were not powerful enough to explain the variability of the rents between the six considered resorts. Therefore these variables were not able to fully control for a possible spatial segmentation. Thus another strategy had to be followed in order to avoid segmentation in the estimates. In our case, the strategy was to introduce geographical interaction terms for the number of rooms in the models.

The statistical tests confirmed the clear segmentation between tourists and residents, as expected on a theoretical basis and depicted by descriptive statistics of

12 The tourists' rents considered for modelling are the ones during the period of February to March 2003. The average weekly rent was 1159 CHF (including bills, 4635 on a monthly basis). It was higher during Christmas and New Year weeks (1398 CHF), lower during the rest of the winter season ( $972 \mathrm{CHF}$ ), and outside of the winter season it was $842 \mathrm{CHF}$. Therefore the nominal change in rent triggered by a change in the landscape quality would have been larger or smaller depending on the season in which the rent would have been modelled for. It however remains that the change is larger for tourists than for residents since even the lowest weekly tourists' average rent ( $842 \mathrm{CHF}$ ) is higher than the monthly average residents' rent (812 CHF throughout the year). 
the rent. However they also underscore that some housing characteristics influence the two submarkets quite differently, whereas other characteristics have an identical implicit price in the hedonic function.

From the perspective of using the housing market as a surrogate market for estimating the value of an environmental amenity like the landscape quality, our prior hypothesis was that the coefficients for such an explanatory variable - i.e. its implicit price elasticity - were different across the tourists' market and the residents'. Tests showed that this is not the case. Conversely, the distance to infrastructure and the average length of ski runs have a different impact across the considered submarkets. Moreover the constant turned out not to be identical in the tourists' hedonic equation and the residents'. Due to the double-log functional form and its multiplicative property, any difference in the value of the constant term "boosts" the impact of a change in whatever characteristic. Thus although the marginal implicit price for the landscape quality can be considered to be identical at the level of the concerned parameter in the two markets in relative terms, the nominal - rather than relative - marginal implicit price differs at the level of the overall model because of the multipicative effect among the included variables and parameters.

Segmentation does not invalidate the hedonic price technique. Rather, it requires a more careful application. As shown in our study, one should of course take care of any spatial segmentation. One should also consider a possible segmentation between groups of consumers, like tourists and residents and accordingly adapt strategies for estimating the hedonic function.

\section{References}

Allen, Markus T., Thomas M. Springer and Neil G. Waller (1995), "Implicit Pricing across Residential Rental Markets", Journal of Real Estate Finance and Economics, 11, pp. 137-151.

Atrinson, Scott. E., and Thomas D. Crocker (1987), "A Baysian Approach to Assessing the Robustness of Hedonic Property Value Studies", Journal of Applied Econometrics, 2, pp. 27-45.

Bana e Costa, Carlos A., and Jean-Claude Vansnick (1999), "The MaCBETH Approach: Basic Ideas, Software, and an Application”, in Nadine Meskens and Marc Roubens (eds), Advances in Decision Analysis, Dordrecht, pp. 131-157.

Benson, Earl D., Julia L. Hansen, Arthur L. Schwartz and Greg T. Smersh (1998), "Pricing Residential Amenities: The Value of a View", Journal of Real Estate Finance and Economics, 16(1), pp. 55-73. 
Bourassa, Steven C., Foort Hamelink, Martin Hoesli and Bryan D. MaCGregor (1999), "Defining Residential Submarkets", Journal of Housing Economics, 8, pp. 160-183.

Bourassa, Steven C., Martin Hoesli and Jian Sun (2003), What's in a View?, Geneva: Research Paper N ${ }^{\circ}$ 79, FAME-International Center for Financial Asset Management and Engineering, Geneva.

Box, George E., and David R. Cox (1964), "An Analysis of Transformations", Journal of Royal Statistical Society, 2, pp. 211-252.

Brush, Robert O., and Elwood L. Shafer, (1975), "Application of a Landscape-Preference Model to Land Management”, in Ervin H. Zube, Robert O. Brush and Julius G. Fabos (eds), Landscape Assessment: Values, Perceptions and Resources, Stroudsburg, Pennsylvania, pp. 168-181.

Cavailhès, Jean, Thierry Brossard, Mohamed Hilal, Daniel Joly, François-Pierre Tourneux, Céline Tritz and Pierre Wavresky (forthcoming), "Pricing the Homebuyer's Countryside View", in Andreas Baranzini, José Ramirez, Caroline Schaerer and Philippe Thalmann (eds), Hedonic Methods in Housing Markets. Pricing Environmental Amenities and Segregation, New York.

Cropper, M. L., L. B. Deck and K. E. McConnell (1988), "On the Choice of Functional Form for Hedonic Price Functions", Review of Economics and Statistics, 70(4), pp. 668-675.

Dale-Johnson, D. (1983), "Clientele Effects on the Demand For Housing Price Appreciation”, Real Estate Economics, 11, pp.382-396.

Des Rosiers, F., M. Thérault, Y. Kestens and P. Villeneuve (2002), "Landscaping and House Values: An Empirical Investigation", Journal of Real Estate Research, 23, pp. 139-161.

Freeman, A. M. (1979), "Hedonic Prices, Property Values and Measuring Environmental Benefits: A Survey of the Issues", The Scandinavian Journal of Economics, 81(2), pp. 154-173.

Goodman, A. C. (1977), "A Comparison of Block Group and Census Tract Data in a Hedonic Housing Price Model", Land Economics, 53, pp.483-487.

Goodman, A. C., and T. G. Thibodeau (1998), "Housing Market Segmentation", Journal of Housing Economics, 7, pp. 121-143.

Goodman, A. C., and T. G. Thibodeau (2003), "Housing Market Segmentation and Hedonic Prediction Accuracy", Journal of Housing Economics, 12(3), pp. 181-201.

Grosclaude, Pascal, and Nils Soguel (1992), "Coûts externes du trafic routier: Evaluation en milieu urbain», Swiss Journal of Economics and Statistics, 128(3), pp.453-469. 
Hidano, N. (2002), The Economic Valuation of the Environment and Public Policy: A Hedonic Approach, Edward Elgar, Cheltenham.

Li, M. M., and H. J. Brown (1980), "Micro-Neighbourhood Externalities and Hedonic Housing Prices", Land Economics, 56, pp. 125-141.

Linneman, P. (1980), "Some Empirical Results on the Nature of the Hedonic Price Function for the Urban Housing Market", Journal of Urban Economics, 8(1), pp. 47-68.

Michaels, R. G., and V. K. Smith (1990), "Market Segmentation and Valuing Amenities with Hedonics Models: The Case of Hazardous Waste Sites", Journal of Urban Economics, 28, pp. 223-242.

Nasar, J. L. (1983), "Environmental Factors, Perceived Distance and Spatial Behavior", Environment and Planning B: Planning and Design, 10, pp. 275-281

Pictet, J., and D. Bollinger (2005), "The Silent Negotiation or How to Obtain Collective Information for Group MCDA without Excessive Discussion”, Journal of Multi-Criteria Decision Analysis, 13(5-6) pp. 199-211.

Powe, N. A., G. D. Garrod, C. F. Brunsdon and K. G. Willis (1997), "Using a Geographical Information System to Estimate an Hedonic Price Model of the Benefits of Woodland Access", Forestry, 70, pp. 139-149.

Schaerer, C., A. Baranzini, J. V. Ramirez and P. Thalmann (2007), "Using the Hedonic Approach to Value Natural Land Uses in an Urban Area: An Application to Geneva and Zurich", Economie publique, 20(1), pp. 1-23.

Schafer, R. (1979), "Racial Discrimination in the Boston Housing Market", Journal of Urban Economics, 6, pp. 176-196.

Salvi, M., P. Schellenbauer and H. Schmidt (2004), Preise, Mieten und Renditen: Der Immobilienmarkt transparent gemacht, Zürcher Kantonalbank, Zürich.

Sirmans, G. S., D. A. MacPherson and E. N. Zietz (2005), "The Composition of Hedonic Pricing Models", Journal of Real Estate Literature, 13(1), pp. 3-43.

Soguel, N., A. Tangerini and J. Pictet (2007), "How to Measure Scope Variables when no Metrics Exist: Application to Landscape Quality Measurement and Hedonic Price Evaluation", Revue d'économie politique, 117(5), pp. 829-844.

Straszheim, M. R. (1975), An Econometric Analysis of the Urban Housing Market, National Bureau of Economic Research, New York.

Taylor, L. O. (2003), “The Hedonic Method", in P. A. Champ, K. J. Boyle and T. C. Brown (eds), A Primer on Nonmarket Valuation, Springer, Dordrecht, pp.331-394. 


\section{SUMMARY}

Market segmentation is an important issue when estimating the implicit price for an environmental amenity from a surrogate market like property. This paper tests the hypothesis of a segmentation of the housing market between tourists and residents and computes the implicit price for natural landscape quality in Swiss alpine resorts. The results show a clear segmentation between both groups of consumers, although tests also show that the estimated coefficient for landscape is similar in the tourists' model and in the residents'. However, since the functional form is non linear, the nominal - rather than relative - value of a change in natural landscape quality is higher in the tourist housing market than in the residents'. Hence, considering the segmentation of the market between tourists and residents is essential in order to provide valid estimates of the nominal implicit price of natural landscape quality. 